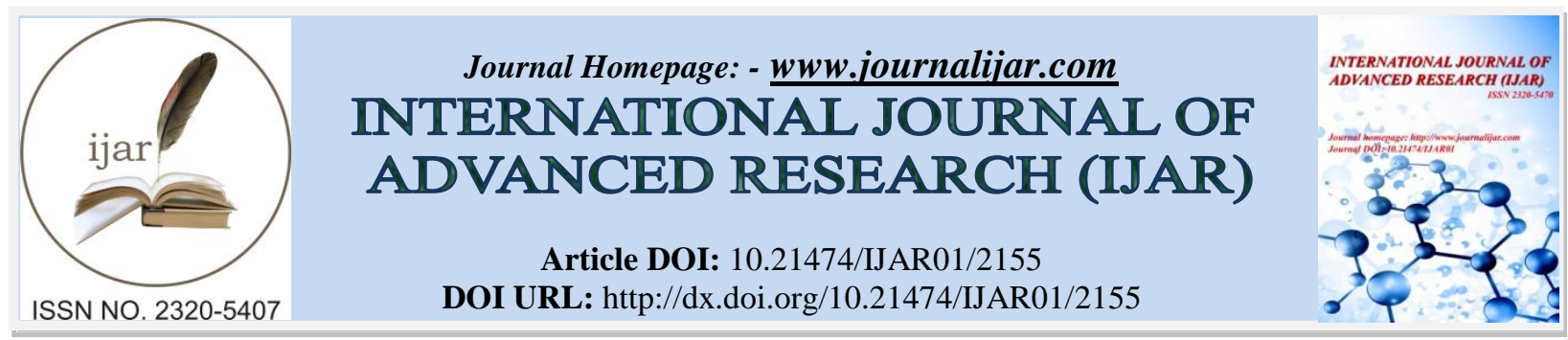

RESEARCH ARTICLE

\title{
STUDIES ON THE MORPHO-ANATOMICAL AND REPRODUCTIVE TRAITS OF MULBERRY HYBRID ( Kajli X Victory -1 ).
}

R. Ravikumara and H. L. Ramesh.

Department of sericulture, Visveswarapura colleage of science, K.R.Road, Banglore-4.

\section{Manuscript Info}

Manuscript History

Received: 25 September 2016

Final Accepted: 27 October 2016

Published: November 2016

Key words:-

kajli, victory-1, leaf yield, stomata

\begin{abstract}
Mulberry due to its cross pollinated and polygenic nature, plants bound to exhibit genetic plasticity. Crossing between highly lobed poor yielding drought and disease resistant variety kajli with high yielding victory-1 is conducted in tropical condition prevailing in Karnataka. Growth, propagation, anatomical and reproductive parameter were recorded in different genotypes in F1 hybrids. Four genotypes selected from more than 1000 seedlings based on morphological brilliance. Reproductive character of the genotypes varied from FH-1>FH-2>FH$3>\mathrm{FH}-4>$. FH-1 is found to possess increased leaf yield $(84 \mathrm{gms}$ from 25 leaves) followed by other genotypes. Varied sex expressions were observed in different seasons of the year. Morphology of the hybrids exhibited better traits compared to kajli and slightly inferior to victory1. Anatomical features like stomata size and stomata frequency observed promising inFH-1 and FH-2 compared to FH-3 and FH-4.
\end{abstract}

Copy Right, IJAR, 2016,. All rights reserved.

\section{Introduction:-}

Mulberry is the unique and only palatable plant substance of silkworm Bombyx mori L. grown in both tropical and temperate conditions of the globe. Due to its heterozygous character, morphological variation is a common phenomenon. Controlled pollination is need of the hour for effective intermixing of characters from a known parent and to induce variations. Increased leaf yield coupled with quality is a major factor in increasing the production of raw silk. Many mulberry genotypes available in nature, except a few popular varieties, rest lack in one or the other morphological traits from the point of rearing silkworm. Unlike the sericulturally advanced countries, India lacks seasonal and regional varieties. Fugundez and Izco, (2011),. Kaya et al.,(2011) and Menon and Srivastava, (1984) worked on the morphologies, leaf yield and biomass production and opined that commercial exploitation in different agro-climatic regions of India by identifying certain intrinsic characters for mulberry improvement programme.

\section{Materials and methods:-}

Mulberry varieties viz,kajli and victory-1 procured from Karnataka state sericulture and development institute (KSSR\&DI), Thalaghattapura, Bangalore and varieties are authenticated by the institute. Kajli is highly lobed, branches very thin and short and belongs to Morus Indica L. diploid in nature, yield of variety is poor but could resist drought and disease conditions ( Amitabh sarkar, 2005). Victory-1 is a product of S30 X Ber776 belongs to Morus Indica L. fast growing with dark green with smooth and glossy surface. Average yield under field condition is around 60 tons/hectare/year.

Corresponding Author:- H. L. Ramesh.

Address:- Department of sericulture, Visveswarapura colleage of science, K. R. Road, Banglore-4. 
Crossing between kajli (Female) and victory-1 (Male) was conducted in germplasm bank, VV Pura College of science, K.R.Road, Bangalore-4. When the female inflorescence bloom, male inflorescence is placed on the female inflorescence and tied with a thin thread. The inflorescence was covered with butter bags to avoid contamination. After a gap of one month, ripened fruits were harvested, seeds extracted and dried in shade for 2 days. Seed sowed in pots and allowed to grow for six months and three replications were maintained. Control seeds of kajli and victory- 1 separately potted for comparison. Four morphological superior genotypes were selected from the seedlings and named First hybrid-1 (FH-1), FH-2, FH-3 and FH-4 and grown for two years (12 pruning). Data recorded was compared with the control.

Stomatal number and frequency was determined by adopting nail polish impression method. Light pink colored nail polish was smeared on the abaxial surface of tender leaves and allowed to dry for 10-15 minutes. Later nail polish was carefully peeled off and observed under the microscope using 40x magnification.

\section{Result And Discussion:-}

Two mulberry genotypes viz,.kajli and victory-1 subjected to hybridization and various morphological, propagation, and reproductive characters and anatomical features of the F1 hybrid was recorded and data is presented.

In the present investigation, out of 1000 seedlings, four genotypes showing better morphological characters like branching nature, leaf area, number of branches, shoot length, internodal distance, survival percentage, sex type were selected. From the investigation, it was observed that the hybrids perform better than kajli and characters intermediary to Kajli and victory-1.

Branching was spreading type in kajli and semi erect in victory-1 compared to hybrids (Table-1)where all the selected genotypes exhibited erect branches and unlobed leaves. Kajli has highly lobed leaves whereas victory-1 possesses unlobedleave.Leaf texture was coriaceous in FH4 and all the other progenies exhibited succulent nature compared coriaceous nature of Kajli and victory-1. Leaf area was highest in FH-1(24.62 X $\left.18.06 \mathrm{~cm}^{2}\right)$, and FH-2 $\left(22.61 \times 16.71 \mathrm{~cm}^{2}\right)$ compared to control plants kajli $\left(10.76 \times 7.88 \mathrm{~cm}^{2}\right)$ and victory-1 $\left(22.42 \mathrm{X} 14.53 \mathrm{~cm}^{2}\right)$-(Table-1)

Shoot length of all the hybrids exhibited better performance over the parents. Survival percentage was more than $90 \%$ in all the hybrids and it was observed $81.97 \%$ i(kajli) and $37.26 \%$ (victory-1). Number of leaves also drastically increased in the hybrids (Table-2).

Reproductive character demonstrated varied nature of hybrids behaving the inflorescence. kajli is strictly a female plant, possess only female catkin but hybrids behave differently in different seasons. All kinds of catkins were observed like male female bisexual(MFBI), male and female (MLFL), female bisexual(FLBI) in winter rainy, summer seasons. In victory-1 though the plants are pre-dominantly male, female and bisexual flowers were also observed. Pollen viability was more than $80 \%$ in all the hybrids whereas victory-1 showed more than $90 \%$ (Table4).Stomatal frequency is considerably reduced in all the hybrids when compared to Kajli and ranged from 485-544 and stomatal size was least atFH-2 (255.63 sq. $\mu \mathrm{m})$ and highest at FH-4 (297.33Sq. $\mu \mathrm{m})$ (Table-3).

Mulberry is polygenic in nature and branching pattern is controlled by polygenes (Ramesh et al., 2012). Leaf lobation is common in higher plants and lobation may be due to heterophylly and some plants shift abruptly from juvenile to adult leaf patterns while shift through a more gradual change with successive leaf development (Elmar Gray and Richard E. Gray, 1987).Katsumata (1982) reported that lobed leaf shape dominates the entire or unlobed one. Due to lack of clear cut idea regarding the inheritance pattern of different characters of economic importance, the breeding technique in mulberry is not very directional.Unlobed leaves found FH-1 (Fig-1), FH-2(Fig-2), FH-3 (Fig-3), FH-4 (Fig-4) may help in increasing the production through enlarging the leaves for more photosynthesis and expected to yield more leaves as supported by (pheasant and clarke,1991) and reported that changes in scion are controlled by the stock through controlled uptake, synthesis and translocation of water, minerals and hormones. The changes that occur in different hybrids confirmed the effect of grafting on morphological changes. Susheelamma and Datta (1993)have correlated small stomatal size with moisture retention capacity maintaining high water potential in mulberry. The hybrids with decreased stomatal frequency and size has the capacity to retain water for longer duration with high yield. 
Table-1:- showing growth parameters of F1 hybrids

\begin{tabular}{|l|l|c|c|c|c|}
\hline Sl. No. & Growth parameters & FH-1 & FH-2 & FH-3 & FH-4 \\
\hline 01 & Number of branches & 20 & 20 & 16 & 18 \\
\hline 02 & Shoot length & 174.67 & 170 & 160 & 158 \\
\hline 03 & Internodal distance(cm) & 8.54 & 7.76 & 6.69 & 6.13 \\
\hline 04 & Weight of 25 leaves (g) & 84 & 79 & 71 & 59 \\
\hline 05 & Leaf area(cm2) & 259 & 247 & 236 & 226 \\
\hline 06 & Petiole weight (g) & 0.855 & 0.557 & 0.325 & 0.654 \\
\hline 07 & Laminar index (\%) & 97.84 & 89.49 & 86.75 & 84.44 \\
\hline 08 & Leaf petiole ratio by length & 6.95 & 5.58 & 4.56 & 4.71 \\
\hline 09 & Leaf petiole ratio by Weight & 10.67 & 9.67 & 8.92 & 8.88 \\
\hline 10 & Leaf shoot ratio & 2.59 & 2.04 & 1.89 & 1.43 \\
\hline
\end{tabular}

\section{Refrences:-}

1. Elmer Gray., Richard E.Gray. 1987. leaflobation patterns in mulberry. castanea52 : 216-224.

2. Fagundez,J., Izco,J.2011. Seed morphology and anatomy of the Mediterranean pentamerous species of Erica.Turkish j.Bot,35: 643-651.

3. H.L.Ramesh, V.N.Yoganandamurthy., Munirajappa.2011. Cochicine induced morphological variation in mulberry variety $\mathrm{M}_{5}$. The Bioscan 6(1):115-118.

4. Kaya, A., Unal,M.,Ozgokce,F.,Dogan,B., Martin,E.2011.Fruit and seed morphology of six species previously placed in Malcolmia in Turkey and their taxonomic value. Turkish Journal of Botany, 35:653-662.

5. Menon,KKG., Srivastava, H.C.1984. Increasing plant productivity through photosynthesis. Proceedings of Indian National Academy of Sciences,93:359-365.

6. Pheasant,J.H., Clarke,J.D.1991. secondary sciences for tropical schools. University of London ,4:8-49.

7. Katsumata. 1982. Phenotypic classification of mulberry. Scientia Horticultarae. Vol.176, 208-217.

8. Susheelamma and Datta. 1993. Adaptability of drought resistant mulberry genotypes. Sericologia, 32(4): 619628 